\title{
Research Article \\ Effect of Melt Temperature and Hold Pressure on the Weld-Line Strength of an Injection Molded Talc-Filled Polypropylene
}

\author{
Yuanxin Zhou and P. K. Mallick \\ Center for Lightweighting Automotive Materials and Processing, University of Michigan-Dearborn, Dearborn, MI 48128, USA \\ Correspondence should be addressed to Yuanxin Zhou; yzhou@mytu.tuskegee.edu
}

Received 12 June 2013; Revised 21 December 2013; Accepted 21 January 2014; Published 5 March 2014

Academic Editor: Mircea Chipara

Copyright ( 2014 Y. Zhou and P. K. Mallick. This is an open access article distributed under the Creative Commons Attribution License, which permits unrestricted use, distribution, and reproduction in any medium, provided the original work is properly cited.

Tensile stress-strain behavior coupled with fractography was used to investigate the weld-line strength of an injection molded $40 \mathrm{w} \%$ talc-filled polypropylene. The relationship between processing conditions, microstructure, and tensile strength was established. Fracture surface of the weld line exhibited skin-core morphology with different degrees of talc particle orientations in the core and in the skin. Experimental results also showed that the thickness of the core decreased and the thickness of the skins increased with increasing melt temperature and increasing hold pressure, which resulted in an increase of yield strength and yield strain with increasing melt temperature and increasing hold pressure. Finally, a three-parameter nonlinear constitutive model was developed to describe the strain softening behavior of the weld-line strength of talc-filled polypropylene. The parameters in this model are the modulus $E$, the strain exponent $m$, and the compliance factor $\beta$. The simulated stress-strain curves from the model are in good agreement with the test data, and both $m$ and $\beta$ are functions of skin-core thickness ratio.

\section{Introduction}

Injection molding is one of the most common manufacturing processes in the polymer industry owing to its versatility, high production rate, short cycle time, and low percentage of scrap. In addition, this process can be used for a large variety of thermoplastic polymers. One of the defects observed in injection molded parts is weld line, which is formed when two or more separate melt fronts traveling from different directions meet and join as the mold cavity is filled [1]. This happens in multigated molds but can also occur when a melt front is divided by inserts used in the mold to create holes or other openings in injection-molded parts. Since weld lines cause reduction in mechanical properties and visual defects, many studies have been conducted to explain the weakness at the weld line. For example, Mielewski et al. [2] have investigated the weld-line morphology of injection molded polypropylene. Tomari et al. [3] have reported Vnotch at weld lines in polystyrene injection moldings. Fellahi et al. [4] investigated the morphology of the weld region in injection-molded high-density polyethylene/polyamide6 blends. In the homopolymer system, the weakness of weld line can be explained by incomplete bonding due to inefficient molecular entanglement at the interface, disturbance of molecular orientation parallel to the flow direction, inefficient diffusion time, existence of voids, and V-shape notch owing to entrapped air or contaminants and notch depth $[5,6]$. On the other hand, loss in weld-line strength in filled and fiber reinforced polymers depends on the shape of the reinforcement. Fisa and Rahmani [7] studied the weld-line strength of injection molded short fiber reinforced polypropylene. The weld line in their study was formed by flow around a circular insert in the mold. They found that the weld-line zone, which extended throughout the thickness, was 2 to $8 \mathrm{~mm}$ wide and the fibers in this zone were oriented in a plane parallel to the weld line. Savadori et al. [8] have observed significant reduction in strength for rubber filled PP/EP blends.

The purpose of this study was to determine the effect of two injection molding processing conditions on the weld line strength of talc-filled polypropylene. Polypropylene is a semicrystalline engineering thermoplastic and is known for its balance of strength, modulus, and chemical resistance. Both polypropylene and polypropylene matrix composite 


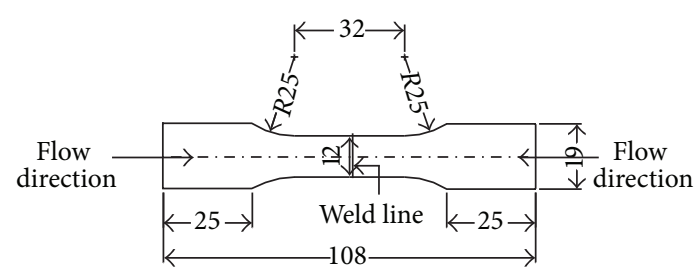

FIgURE 1: Schematic of the tension specimen with weld line at the mid length (dimensions are in $\mathrm{mm}$.).

have many potential applications in automobiles where creep resistance, stiffness, and some toughness are required in addition to weight savings. Mechanical behavior of polypropylene and its composites has been the subject of numerous studies over the last few years. Some of these research studies have investigated the relationship between the mechanical behavior of polypropylene, microstructure, and processing conditions. Diez-Gutierrez et al. [9] have reported the dynamic mechanical analysis of injection-molded discs of polypropylene and untreated and silane-treated talc-filled polypropylene composites. Li and Cheung [10] have investigated the effect of mold temperature on the formation of $\alpha / \beta$ polypropylene blends in injection molding. All these results show that the mechanical behavior of polypropylene and its composites is sensitive to the injection molding processing conditions. However, the effect of processing conditions on the weld-line strength of talc-filled polypropylene composites has not been reported in the past.

\section{Experimental}

The material investigated in this study was a $40 \mathrm{w} \%$ talcfilled polypropylene homopolymer. The average flow rate of this material was $6.8 \mathrm{~g} / 10 \mathrm{~min}$. The melting point of the polypropylene matrix was $160^{\circ} \mathrm{C}$. The injection-molded plate thickness was $2.5 \mathrm{~mm}$. A 90-ton Toyo injection molding machine was used to mold these plates. Three different melt temperatures were considered, namely, 209, 232, and $277^{\circ} \mathrm{C}$. The peak injection pressure was $103 \mathrm{MPa}$ for all plates, but the hold pressure was varied at three levels, namely, 27.6, 55.2, and $82.7 \mathrm{MPa}$. The mold temperature was maintained at $35^{\circ} \mathrm{C}$. The following two groups of plates were injection molded:

(1) group I: hold pressure $=55.2 \mathrm{MPa}$ and melt temperature $=209,232$, and $277^{\circ} \mathrm{C}$,

(2) group II: melt temperature $=232^{\circ} \mathrm{C}$ and hold pressure $=27.6,55.2$, and $82.7 \mathrm{MPa}$.

Dog-bone shaped specimens were prepared from the injection molded plates with weld line. The specimen dimensions were $100 \mathrm{~mm}$ in overall length, $25 \mathrm{~mm}$ in gage length, and $12.7 \mathrm{~mm}$ in gage width (Figure 1). The weld line, shown as located at the mid length of the tensile specimens, was formed in the plates as the two melt fronts with the opposite flow directions joined together at the mid length.

Uniaxial tensile tests were performed on an MTS servohydraulic testing machine. Three specimens were tested

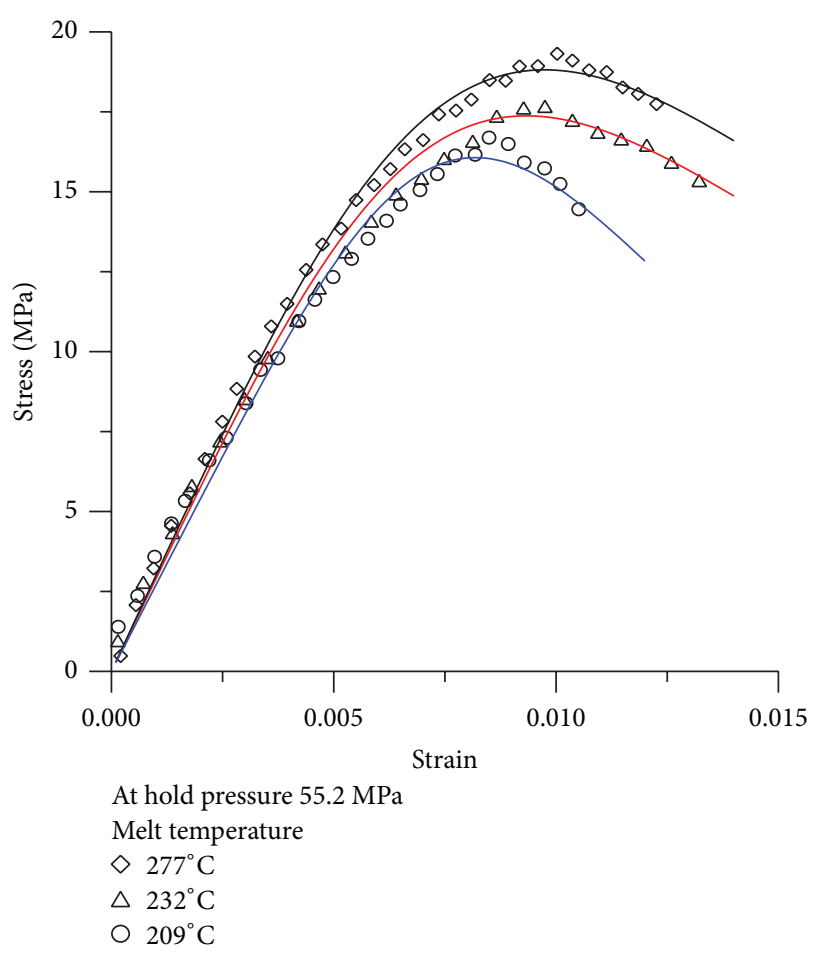

FIGURE 2: Effect of melt temperature on the stress-strain curves of talc-filled polypropylene with weld line.

for each processing condition. The tensile tests were conducted at $1.25 \mathrm{~mm} / \mathrm{min}$, which is equivalent to a strain rate of $0.05 \mathrm{~min}^{-1}$. Three parameters were evaluated from each stress-strain curve: elastic modulus $(E)$, yield strength $\left(\sigma_{y}\right)$, and yield strain $\left(\varepsilon_{y}\right)$. Elastic modulus or Young's modulus is the initial slope of the stress-strain curve. Yield strength is assumed to be the maximum stress observed in each stress-strain diagram and the strain corresponding to the yield strength is the yield strain. During the tensile tests, all specimens were observed to break at the weld zone.

\section{Results and Discussion}

Figures 2 and 3 show the tensile stress-strain curves of talc-filled polypropylene with weld line under the different processing conditions. It can be observed in these figures that the stress-strain diagrams are nonlinear even at strains lower than the yield strain. Each curve shows a maximum stress, which is assumed to be the yield strength of the material at the weld line. After reaching the yield point, stress decreased steadily with strain until fracture occurred at the weld zone.

Figure 2 shows the effect of melt temperature on the tensile behavior of talc-filled polypropylene with weld line. The yield strength and yield strain increased by $9.3 \%$ and $26.6 \%$, respectively, as the melt temperature was increased from $209^{\circ} \mathrm{C}$ to $277^{\circ} \mathrm{C}$. But the effect of melt temperature on the modulus is relatively small for the three melt temperatures investigated. Figure 3 shows the effect of hold pressure on the tensile behavior of talc-filled polypropylene with weld line. Increasing the hold pressure increases the yield strength, yield 
TABLE 1: Weld-line tensile properties of talc filled polypropylene at different processing conditions.

\begin{tabular}{lcccccc}
\hline $\begin{array}{l}\text { Melt } \\
\begin{array}{l}\text { temperature } \\
\left({ }^{\circ} \mathrm{C}\right)\end{array}\end{array}$ & $\begin{array}{c}\text { Hold pressure } \\
(\mathrm{MPa})\end{array}$ & $\begin{array}{c}\text { Modulus } \\
(\mathrm{GPa})\end{array}$ & $\begin{array}{c}\text { Yield strength } \\
(\mathrm{MPa})\end{array}$ & $\begin{array}{c}\text { Yield strain } \\
(\%)\end{array}$ & $\begin{array}{c}\beta \\
(1 / \mathrm{MPa})\end{array}$ \\
\hline 209 & 55.2 & $6.56( \pm 0.23)$ & $17.5( \pm 0.31)$ & $0.79( \pm 0.04)$ & 2.81 & 113 \\
232 & 55.2 & $6.84( \pm 0.19)$ & $17.9( \pm 0.40)$ & $0.91( \pm 0.04)$ & 2.79 & 90.4 \\
277 & 55.2 & $6.94( \pm 0.20)$ & $19.1( \pm 0.34)$ & $1.00( \pm 0.07)$ & 2.57 & 28.2 \\
232 & 27.6 & $6.71( \pm 0.24)$ & $17.1( \pm 0.23)$ & $0.86( \pm 0.04)$ & 2.87 & 149 \\
232 & 82.7 & $6.92( \pm 0.20)$ & $22.5( \pm 0.30)$ & $1.31( \pm 0.03)$ & 2.32 & 6.9 \\
\hline
\end{tabular}

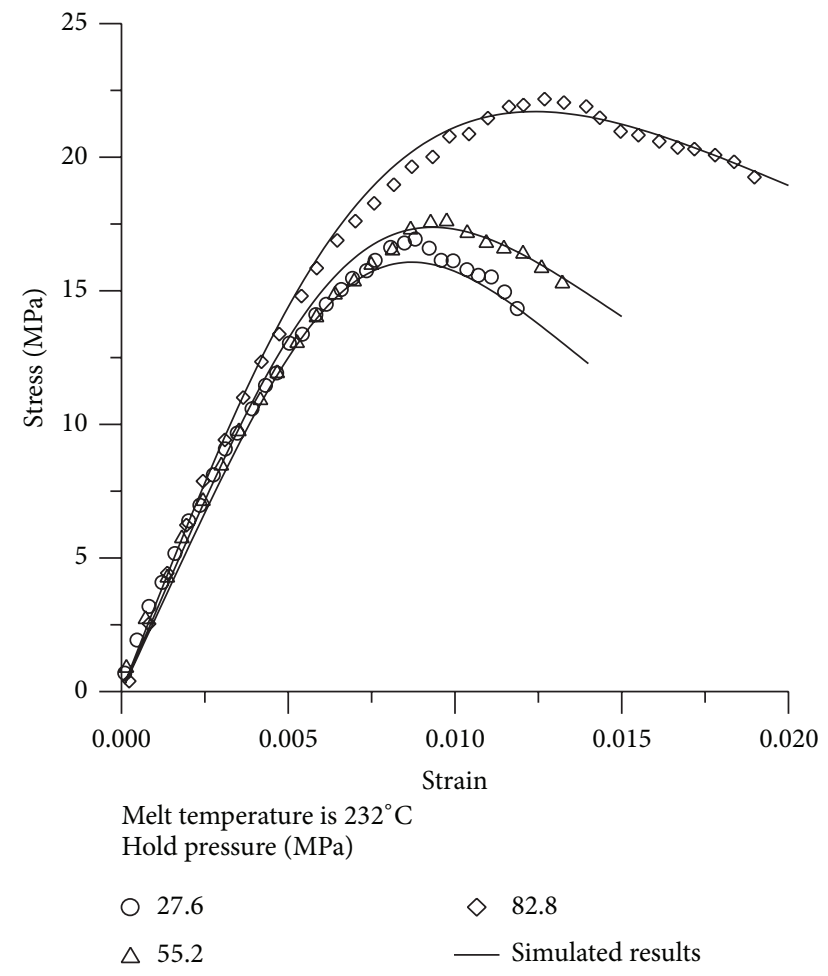

FIGURE 3: Effect of hold pressure on the stress-strain curves of talcfilled polypropylene with weld line.

strain, and failure strain. But the modulus is not sensitive to hold pressure. The tensile properties of material with different processing conditions are listed in Table 1.

From Figures 2 and 3 and Table 1, it can be concluded that the weld-line yield properties of talc-filled polypropylene are sensitive to the two processing conditions considered. Figures 4 and 5 show that the variation of yield strength $\sigma_{y}$ and yield strain $\varepsilon_{y}$ with melt temperature and hold pressure can be represented by linear relationships. The following two linear relationships are proposed:

$$
\begin{aligned}
& \sigma_{y}=\sigma_{y}\left(T_{0}, P_{0}\right)\left[1+J_{\text {melt }}\left(T-T_{0}\right)\right]\left\lfloor 1+J_{\text {pressure }}\left(P-P_{0}\right)\right\rfloor, \\
& \varepsilon_{y}=\varepsilon_{y}\left(T_{0}, P_{0}\right)\left[1+L_{\text {melt }}\left(T-T_{0}\right)\right]\left\lfloor 1+L_{\text {pressure }}\left(P-P_{0}\right)\right\rfloor,
\end{aligned}
$$

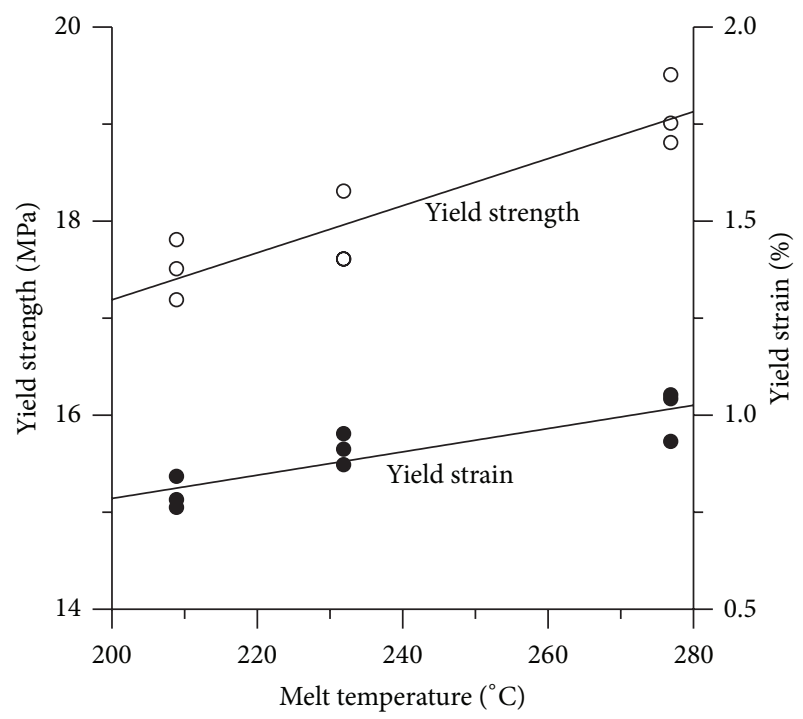

FIGURE 4: Effect of melt temperature on the yield strength and yield strain.

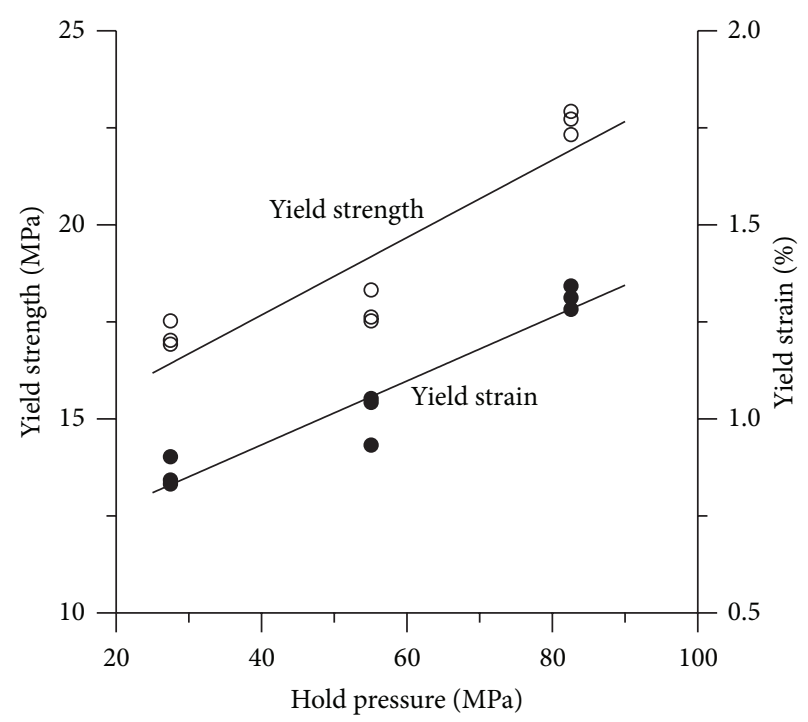

FIGURE 5: Effect of hold pressure on the yield strength and yield strain. 


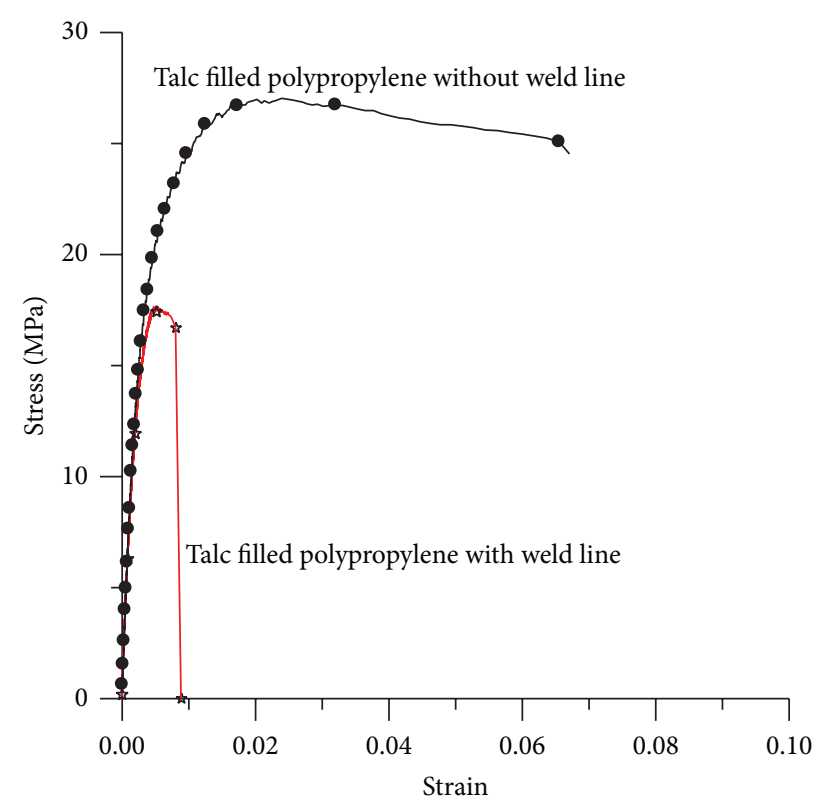

FIGURE 6: Stress-strain curves of talc-filled polypropylene with and without weld line.

where $J_{\text {melt }}, L_{\text {melt }}$ and $J_{\text {pressure }}, L_{\text {pressure }}$ are melt temperature sensitivity factor and hold pressure sensitivity factor. $T_{0}$ and $P_{0}$ are reference melt temperature and reference mold pressure. $\sigma_{y}\left(T_{0}, P_{0}\right)$ and $\varepsilon_{y}\left(T_{0}, P_{0}\right)$ are the reference yield strength and yield strain. Mathematically, $J_{\text {melt }}, L_{\text {melt }}$ and $J_{\text {pressure }}, L_{\text {pressure }}$ can be obtained by

$$
\begin{gathered}
J_{\text {melt }}=\frac{\partial \sigma_{Y} / \sigma_{Y}\left(T_{0}, P_{0}\right)}{\partial T} \text { or } \quad L_{\text {melt }}=\frac{\partial \varepsilon_{Y} / \varepsilon_{Y}\left(T_{0}, P_{0}\right)}{\partial T}, \\
J_{\text {pressure }}=\frac{\partial \sigma_{Y} / \sigma_{Y}\left(T_{0}, P_{0}\right)}{\partial P} \text { or } \quad L_{\text {pressure }}=\frac{\partial \varepsilon_{Y} / \varepsilon_{Y}\left(T_{0}, P_{0}\right)}{\partial P} .
\end{gathered}
$$

Assuming the reference melt temperature $T_{0}=232^{\circ} \mathrm{C}$ and reference hold pressure $P_{0}=55.2 \mathrm{MPa}$, one can obtain the average values of the melt temperature sensitivity factor and the hold pressure sensitivity factor as

$$
\begin{array}{cl}
J_{\text {melt }}=0.024 /{ }^{\circ} \mathrm{C}, & L_{\text {melt }}=0.0029 /{ }^{\circ} \mathrm{C} \\
J_{\text {pressure }}=0.098 / \mathrm{MPa}, & L_{\text {pressure }}=0.0082 / \mathrm{MPa} .
\end{array}
$$

Figure 6 shows comparison of stress-strain curves for talc-filled polypropylene with weld and without weld line. When the weld line was introduced, the yield strength, yield strain, and failure strain decreased by $35 \%, 73 \%$, and $92 \%$, respectively. But the presence of weld line does not influence the modulus. After the yield strain is reached, the weld-line specimen breaks quickly, with very little additional deformation, indicating that the weld line is a weak zone in the material. According to Merah et al. [11], weld line is a brittle zone; the yield strain and failure strain for weldline specimens have the same value. But in the talc-filled polypropylene with weld line, $0.3-0.6 \%$ plastic strain was

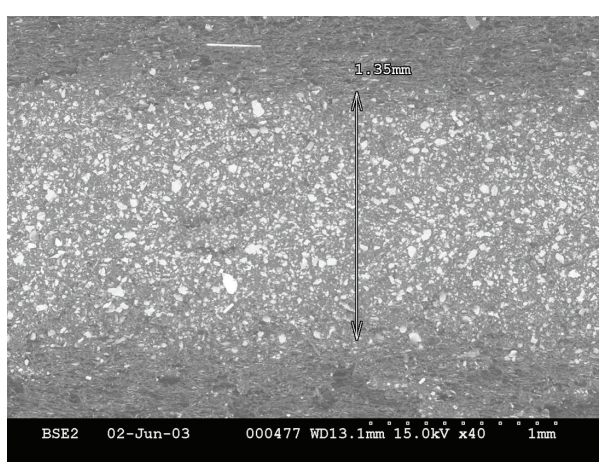

(a)

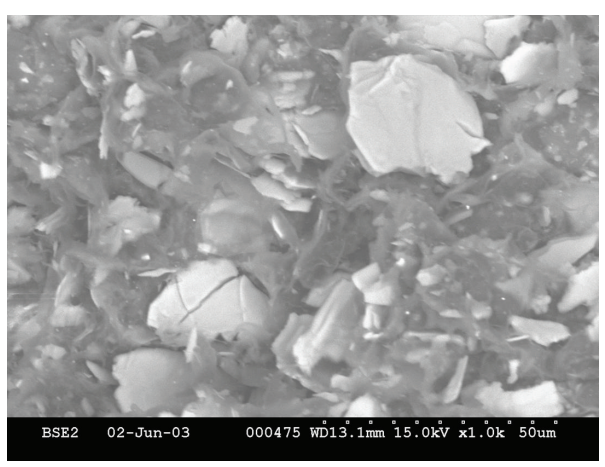

(b)

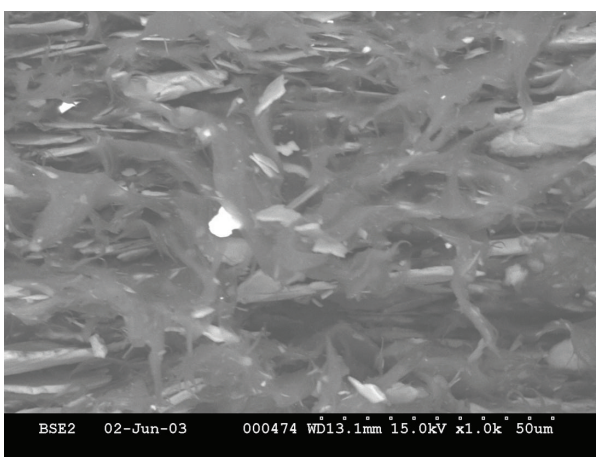

(c)

FIGURE 7: Skin-core morphologyof the weld zone of talc-filled polypropylene with weld-line injection molded at 55.2 MPa hold pressure and $232^{\circ} \mathrm{C}$ melt temperature. (a): general view; (b): in the core (white band); (c): in the skin (darker zone).

observed after yielding (as shown in Figures 2 and 3). In Figure 6, strain softening behavior was found for specimens with and without weld line, which was conjectured to be due to the strain softening behavior of polypropylene matrix [12].

To investigate the failure mechanism of the weld line, the fracture surfaces at the weld line were examined in a scanning electron microscope. Fracture surface in Figure 7(a) exhibits skin-core morphology with different degrees of talc particle orientations in the core and in the skin. A "white band" can be observed in the center section of the fracture surface. It consists of talc particles with their surface oriented normal to the flow direction (Figure 7(b)). No matrix material can be seen adhering to the particles, indicating poor or no adhesion 


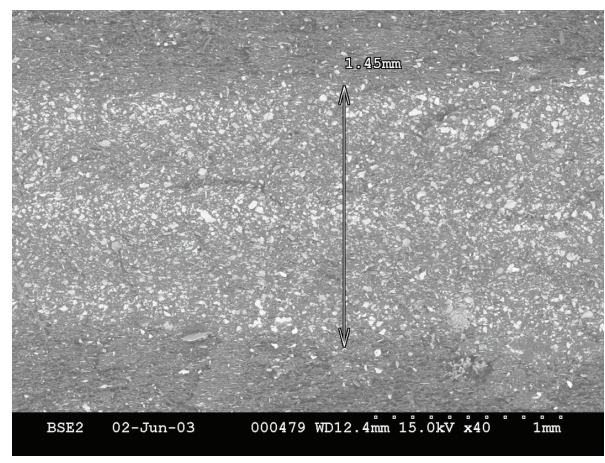

(a)

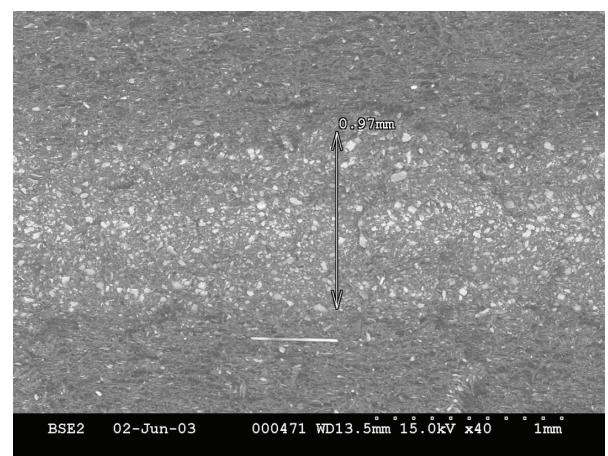

(b)

FIGURE 8: Skin-core morphologyat the weld zone of talc-filled polypropylene injection molded at two different hold pressures ((a): 27.6 $\mathrm{MPa}$ and (b): $82.7 \mathrm{MPa}$ ) and $232^{\circ} \mathrm{C}$ melt temperature.

between the talc particles and the polypropylene matrix. In this area, the particles prevented the polymer chain to bridge across the weld line interface to form a strong bond and the orientation of the molecules is parallel to the weld-line rather than across it. Brittle fracture of talc particles can also be observed in Figure 7(b). Talc particles outside the core tend to be parallel to the flow direction (same as the tensile test direction). The color of this area is dark. Polymer chains in this area can easily bridge across the weld line to form a strong bond between the two sides and the orientation of the molecules is normal to the weld line rather than parallel to it. Magnification of the fracture initiation site was shown in Figure 7(c). The matrix material was drawn in the tensile stress direction and fibrillated around the talc particles. The ductility of weld line can be mainly attributed to the large elongation of polypropylene in the dark area.

The formation of skin-core morphology along the weld line of talc-filled polypropylene can be explained by referring to the viscous flow behavior of the liquid material as it flows in the injection molding cavity. The shear stress in the flow channel decreases from its highest value at the cavity walls to a near-zero value at the center. Near the cavity walls, the platy talc particles as well as the polymer molecules become oriented parallel to the flow direction as a result of the high shear stress in this area. But near the center, where the shear stress is the lowest and the flow velocity is the highest, the particles turn to normal to the flow direction.

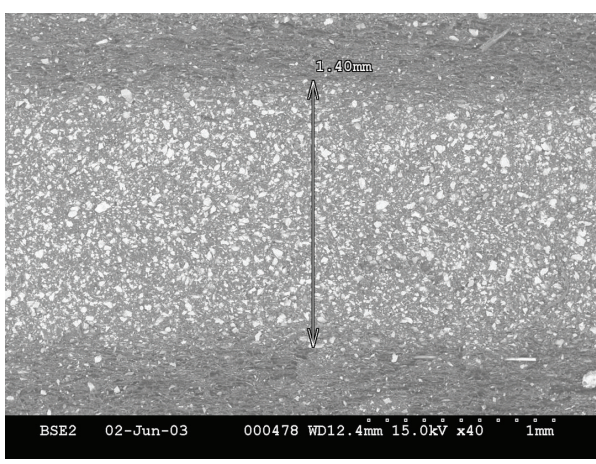

(a)

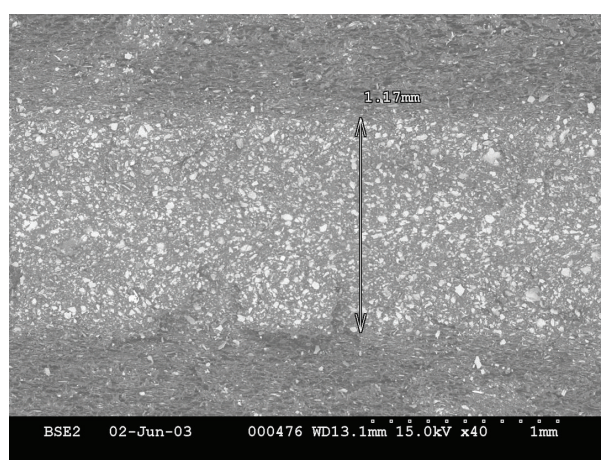

(b)

FIGURE 9: Skin-core morphologyat the weld zone of talc-filled polypropylene injection molded at two different melt temperatures ((a): $209^{\circ} \mathrm{C}$ and (b): $277^{\circ} \mathrm{C}$ ) and $55.2 \mathrm{MPa}$ hold pressure.

Figures $8(\mathrm{a})$ and $8(\mathrm{~b})$ show the fracture surfaces of the specimens injection molded at hold pressures $27.6 \mathrm{MPa}$ and 82.7 MPa, respectively. The thickness of the "white band" decreased with the increasing hold pressure; more and more talc particles tend to be parallel to the flow direction (tensile direction). Figures 9(a) and 9(b) show the fracture surfaces of the specimens injection molded at melt temperatures $209^{\circ} \mathrm{C}$ and $277^{\circ} \mathrm{C}$, respectively. Here also, the thickness of the "white band" decreased with increasing melt temperature.

From Figures 7-9, it can be concluded that the total crosssectional area of the weld line can be divided into well bonded area (dark zone) and nonbonded area (white band). If we assume that the total load is shared by the two areas, then the yield strength of the weld line can be expressed as

$$
\sigma_{y}=\sigma_{0}\left(\frac{A_{0}-A_{N}}{A_{0}}\right)+\sigma_{N}\left(\frac{A_{N}}{A_{0}}\right)
$$

where $\sigma_{0}, \sigma_{N}$ are the yield strengths of the injection molded part without and with "white band." $A_{0}$ is the total crosssectional area of the specimen and $A_{N}$ is cross-sectional area of the nonbonded white area. Furthermore, if we assume that both dark and white bands have the same width as the specimen width, the skin-core thickness ratio can be defined as

$$
R_{T}=\frac{A_{N}}{A_{0}}=\frac{T_{W}}{T_{0}},
$$




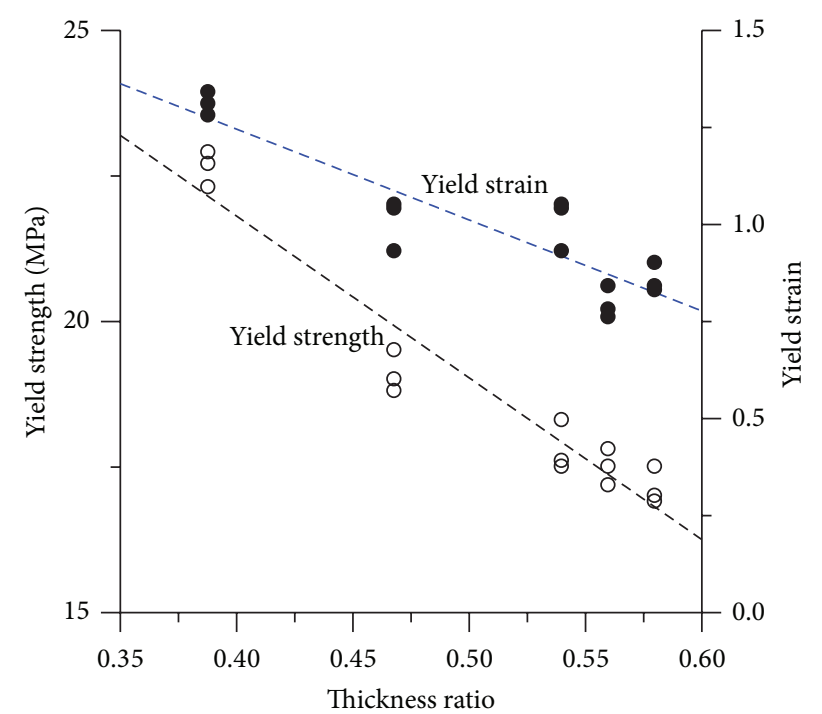

FIGURE 10: Effect of skin-core thickness ratio on weld-line yield strength and strain.

where $T_{w}$ and $T_{0}$ are thickness of white band and thickness of entire specimen. Equation (4) can then be rewritten as

$$
\sigma_{y}=\sigma_{0}-\left(\sigma_{0}-\sigma_{N}\right) R_{T} .
$$

Similarly, the yield strain of the weld line can be expressed as

$$
\varepsilon_{y}=\varepsilon_{0}-\left(\varepsilon_{0}-\varepsilon_{N}\right) R_{T} .
$$

Figure 10 shows the variation between yield strength, yield strain, and thickness ratio. Linear relationships are observed and the constants were simulated by using the least square method

$$
\begin{gathered}
\sigma_{0}=32.6 \mathrm{MPa}, \quad \sigma_{N}=5.4 \mathrm{MPa}, \\
\varepsilon_{0}=2.30 \%, \quad \varepsilon_{N}=-0.3 \% .
\end{gathered}
$$

Small value in $\sigma_{N}$ and negative value in $\varepsilon_{N}$ declare the loading bearing capability of the "white band" can be ignored.

\section{One-Dimensional Constitutive Equation}

In this section, we apply a one-dimensional constitutive equation that was developed earlier [13] for welded talc-filled polypropylene. The total strain is assumed to be additively decomposed into elastic and inelastic parts,

$$
\varepsilon=\varepsilon_{e}+\varepsilon_{i},
$$

where $\varepsilon_{e}$ and $\varepsilon_{i}$ represent the elastic and inelastic strains, respectively. The elastic strain is assumed to be path independent, such that

$$
\varepsilon_{e}=\frac{\sigma}{E},
$$

where $E$ is elastic modulus of the material and $\sigma$ is the stress. The inelastic strain, $\varepsilon_{i}$, is assumed to be a function of stress and total strain in the following way:

$$
\varepsilon_{i}=\beta \sigma \varepsilon^{m} \text {. }
$$

Substituting (10) and (11) into (9) gives

$$
\sigma=\frac{E \varepsilon}{1+E \beta \varepsilon^{m}} .
$$

Equation (12) represents the constitutive equation. At small strains, $E \beta \varepsilon^{m} \ll 1$, one can obtain

$$
\frac{d \sigma}{d \varepsilon}=\frac{E+(1-m) E^{2} \beta \varepsilon^{m}}{\left[1+E \beta \varepsilon^{m}\right]^{2}} \approx E .
$$

Therefore, at very small strains, (12) approximates an elastic material. At large strains, $E \beta \varepsilon^{m} \gg 1$, and (12) can be simplified as

$$
\sigma=\left\{\begin{array}{lll}
\frac{1}{\beta} \varepsilon^{1-m} & m<1 & \text { Strain Hardening, } \\
\frac{1}{\beta} & m=1 & \text { Critical Value } \\
\frac{1}{\beta} \varepsilon^{1-m} & m>1 & \text { Strain Softening. }
\end{array}\right.
$$

To determine the parameters in the constitutive equation, (12) is written as

$$
\begin{gathered}
\frac{\varepsilon}{\sigma}=\beta \varepsilon^{m}+\frac{1}{E} \\
\ln \left(\frac{\varepsilon}{\sigma}-\frac{1}{E}\right)=\ln \beta+m \ln \varepsilon .
\end{gathered}
$$

Equation (16) represents a linear equation when $\ln [\varepsilon / \sigma-$ $1 / E]$ is plotted against $\ln \varepsilon$. From the slope and intercept of the linear plot, $m$ and $\beta$ of the material can be obtained by using the least square method. Plots of $\ln [\varepsilon / \sigma-1 / E]$ versus $\ln \varepsilon$ of talc-filled polypropylene with weld line, shown in Figure 11, are linear at different processing conditions. The values of $m$ and $\beta$ obtained from these plots are listed in Table 1.

Figure 12 shows the compliance factor $\beta$ and strain exponent $m$ plotted as a function of thickness ratio. It can be observed from this figure that both $m$ and $\beta$ increased with increasing thickness ratio. Their relationships can be expressed by the following equations:

$$
\begin{gathered}
m=1.22+2.87 R_{T}, \\
\beta(1 / \mathrm{MPa})=0.014 \exp \left(7.68 R_{T}\right) .
\end{gathered}
$$

Substituting elastic modulus $E$, compliance factor $\beta$, and strain exponent $m$ into (12), the simulated stress-strain plots were drawn in Figures 2 and 3 and they seem to fit the experimental data well.

\section{Conclusions}

Weld-line yield strength, yield strain, and failure strain of talc-filled polypropylene increase with increasing melt temperature and increasing hold pressure. The effects of these two injection molding process parameters are explained in terms of their influence on the skin-core morphology observed on the fracture surfaces in the weld zone. The core contained talc 


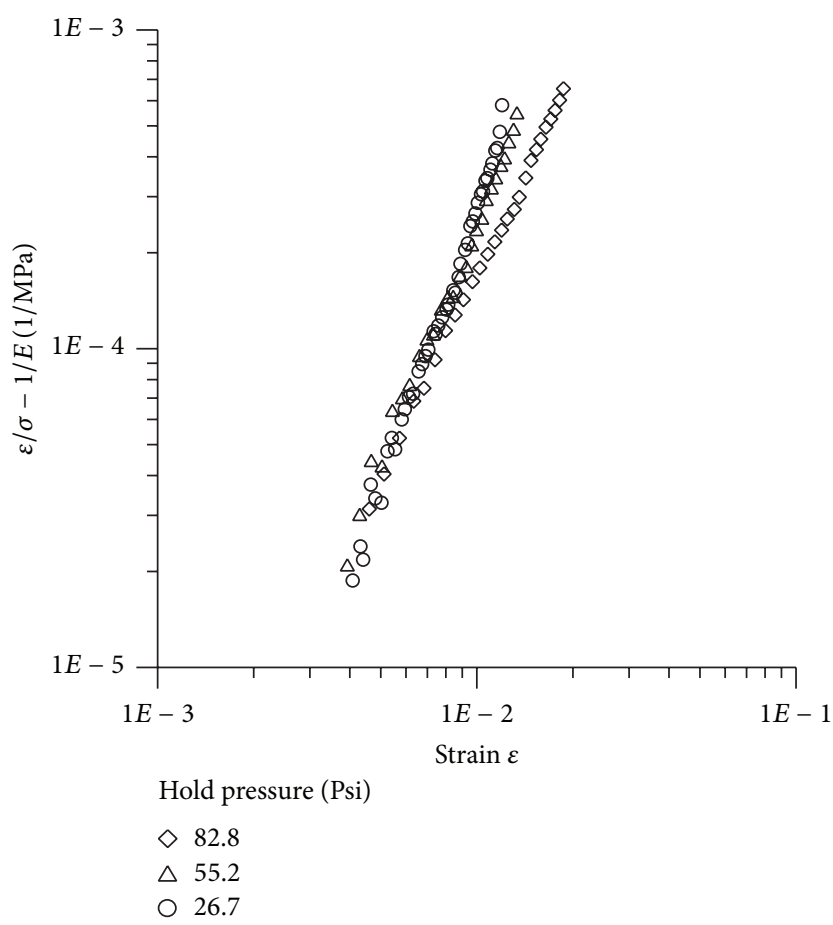

(a)

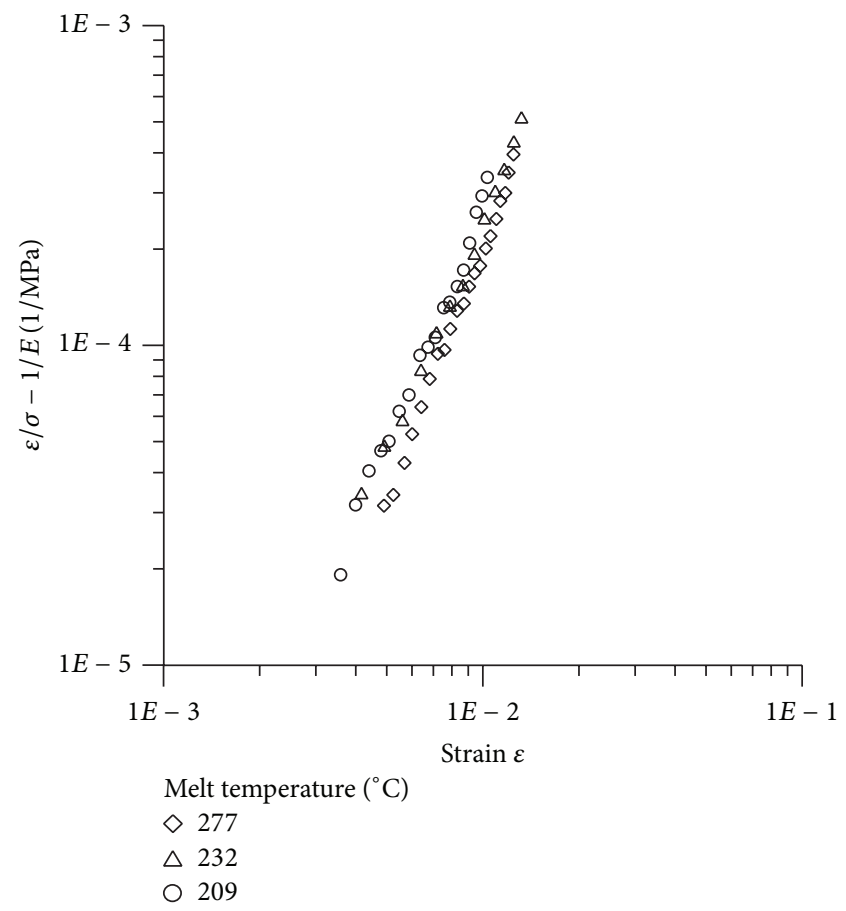

(b)

Figure 11: Plots of $[\varepsilon / \sigma-1 / E]$ versus $\varepsilon$ in $\log$-log scale for $40 \mathrm{w} \%$ talc-filled polypropylene with weld line ((a): with different hold pressure; (b): with different melt temperature).

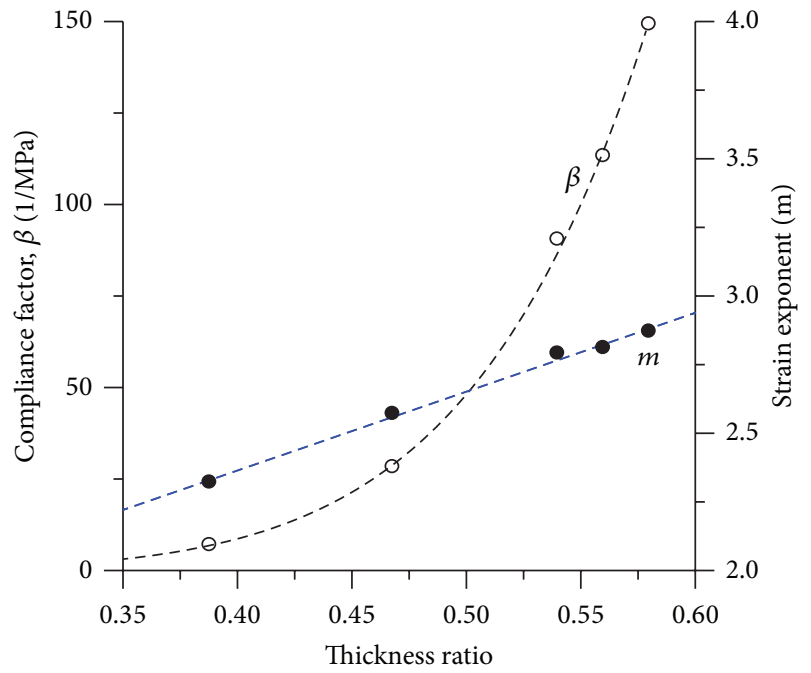

FIGURE 12: Compliance factor $\beta$ and strain exponent $m$ as a function of skin-core thickness ratio $R_{T}$.

particles that were oriented normal to the loading direction and the skins contained talc particles oriented parallel to the loading direction. The thickness of the core decreased and the thickness of the skins increased with increasing melt temperature and increasing hold pressure. A three-parameter nonlinear constitutive model is applied to describe the stressstrain curves of the talc-filled polypropylene. The parameters in this model are the modulus $E$, the strain exponent $m$, and the compliance factor $\beta$. Both $m$ and $\beta$ are sensitive to the skin-score thickness ratio.

\section{Conflict of Interests}

The authors declare that there is no conflict of interests regarding the publication of the paper.

\section{References}

[1] N. Mekhilef, A. Ait-Kadi, and A. Ajji, "Weld lines in injectionmoulded immiscible blends: model predictions and experimental results," Polymer, vol. 36, no. 10, pp. 2033-2042, 1995.

[2] D. F. Mielewski, D. R. Bauer, P. J. Schmitz, and H. Van Oene, "Weld line morphology of injection molded polypropylene," Polymer Engineering and Science, vol. 38, no. 12, pp. 2020-2028, 1998.

[3] K. Tomari, S. Tonogai, T. Harada et al., "V-notch at weld lines in polystyrene injection moldings," Polymer Engineering and Science, vol. 30, no. 15, pp. 931-936, 1990.

[4] S. Fellahi, B. D. Favis, and B. Fisa, "Morphological stability in injection-moulded high-density polyethylene/polyamide- 6 blends," Polymer, vol. 37, no. 13, pp. 2615-2626, 1996.

[5] J. K. Kim, S. H. Park, T. O. Hyun, and H. K. Jeon, "The effect of weld-lines on the morphology and mechanical properties of amorphous polyamide/poly(ethylene-ran-propylene) blend with various amounts of an in situ compatibilizer," Polymer, vol. 42 , no. 5, pp. 2209-2221, 2001. 
[6] O. G. Ersoy and N. Nugay, "A new approach to increase weld line strength of incompatible polymer blend composites: selective filler addition," Polymer, vol. 45, no. 4, pp. 1243-1252, 2004.

[7] B. Fisa and M. Rahmani, "Weldline strength in injection molded glass fiber-reinforced polypropylene," Polymer Engineering \& Science, vol. 31, no. 18, pp. 1330-1336, 1991.

[8] A. Savadori, A. Pelliconi, and D. Romanini, "Weld line resistance in polypropylene composites," Plastics and Rubber Processing and Applications, vol. 3, no. 3, pp. 215-221, 1983.

[9] S. Diez-Gutierrez, M. A. Rodriguez-Perez, J. A. De Saja, and J. I. Velasco, "Dynamic mechanical analysis of injection-moulded discs of polypropylene and untreated and silane-treated talcfilled polypropylene composites," Polymer, vol. 40, no. 19, pp. 5345-5353, 1999.

[10] J. X. Li and W. L. Cheung, "Effect of mould temperature on the formation of $\alpha / \beta$ polypropylene blends in injection moulding," Journal of Materials Processing Technology, vol. 63, no. 1-3, pp. 472-475, 1997.

[11] N. Merah, M. Irfan-ul-Haq, and Z. Khan, "Temperature and weld-line effects on mechanical properties of CPVC," Journal of Materials Processing Technology, vol. 142, no. 1, pp. 247-255, 2003.

[12] Y. Zhou and P. K. Mallick, "Effects of temperature and strain rate on the tensile behavior of unfilled and talc-filled polypropylene. Part I: experiments," Polymer Engineering and Science, vol. 42, no. 12, pp. 2449-2460, 2002.

[13] Y. Zhou and P. K. Mallick, "Effects of temperature and strain rate on the tensile behavior of unfilled and talc-filled polypropylene. Part II: constitutive equation," Polymer Engineering and Science, vol. 42, no. 12, pp. 2461-2470, 2002. 

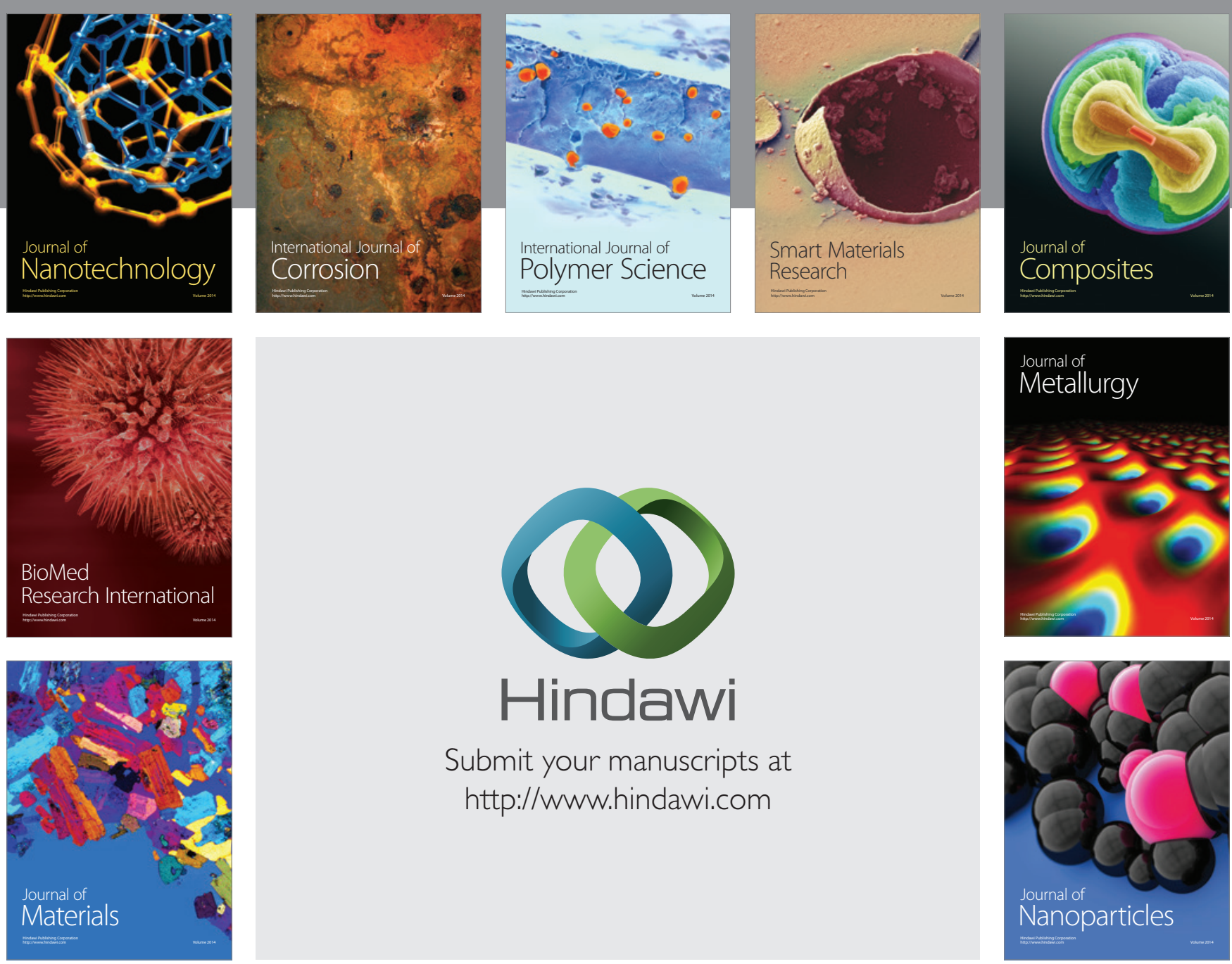

Submit your manuscripts at http://www.hindawi.com
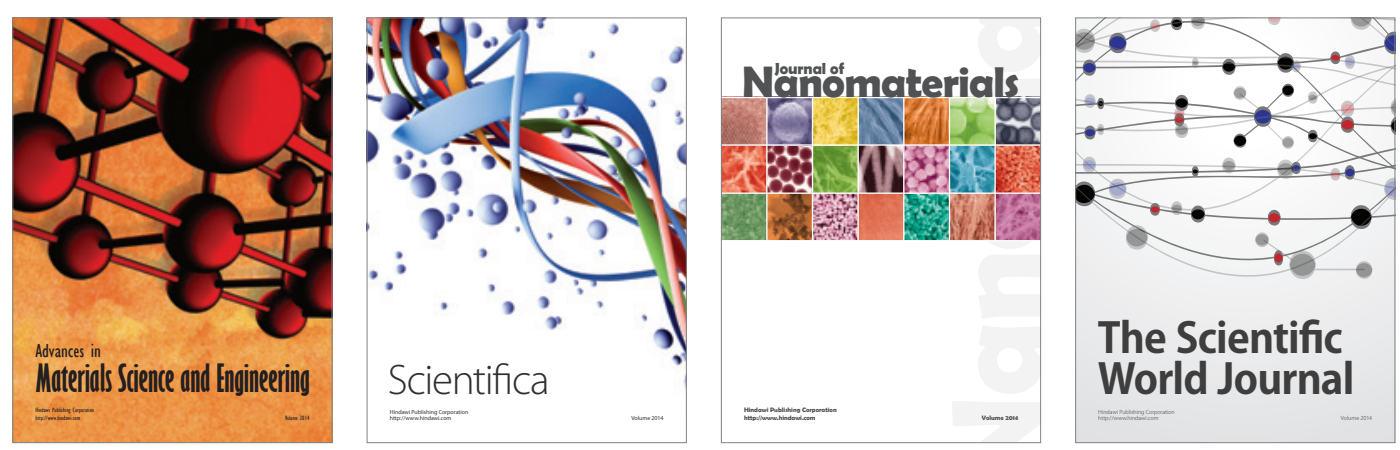

\section{The Scientific World Journal}
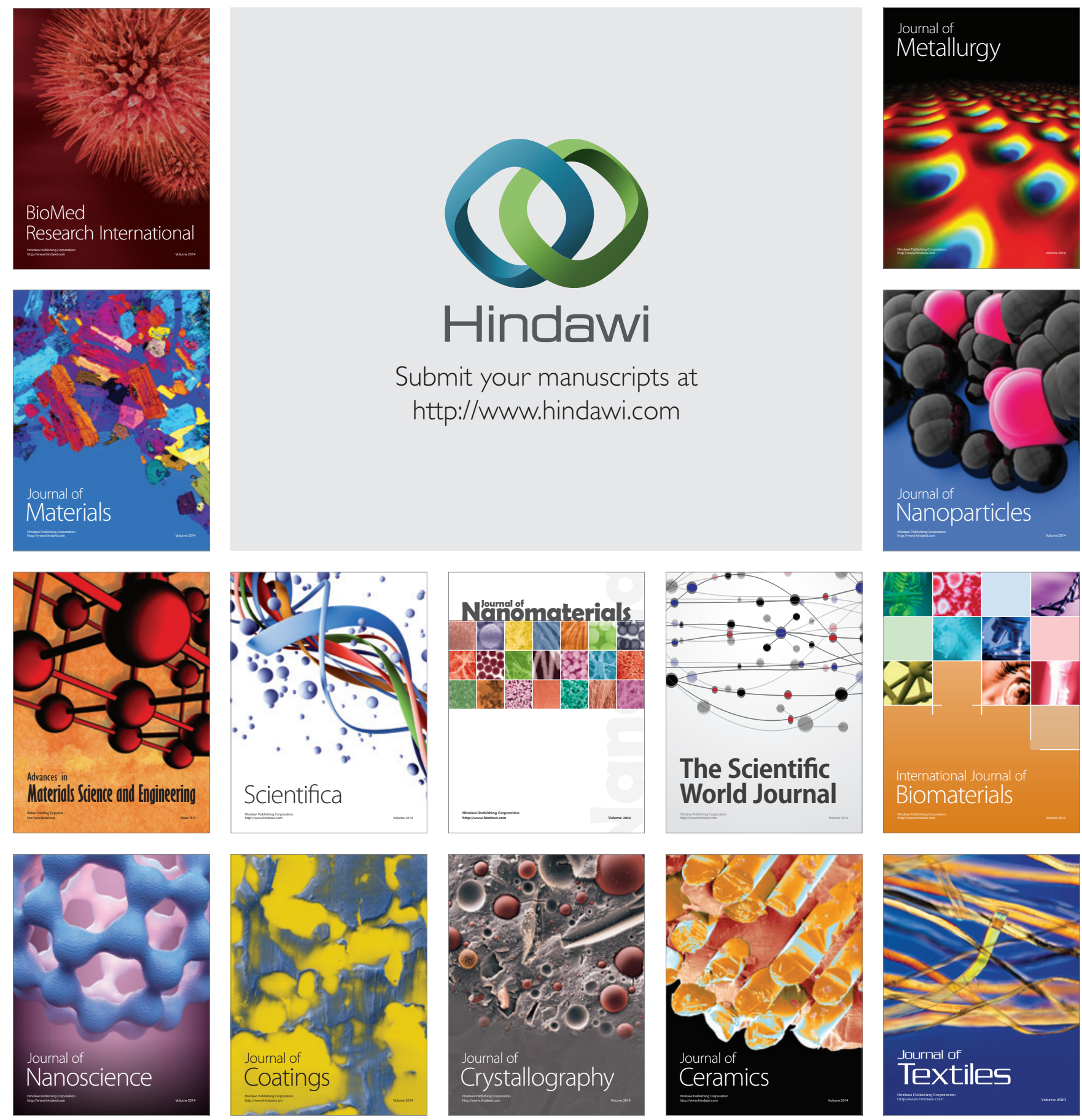